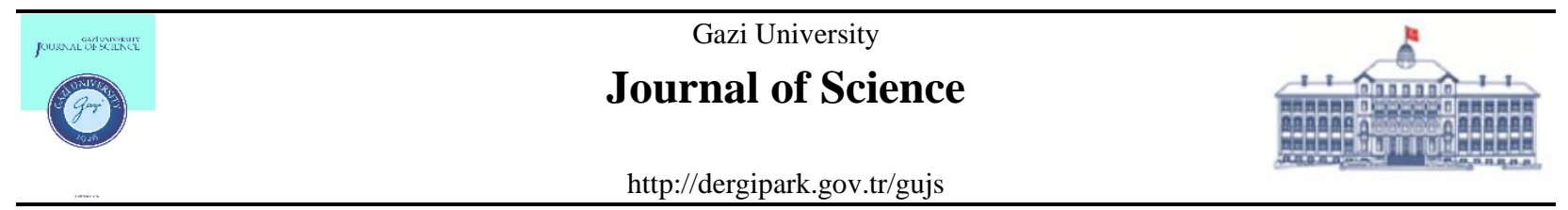

\title{
Investigation Effect of Zinc Nanoparticles on The Mechanical and Anticorrosion Properties of Epoxy Coatings on Stainless Steel Surface
}

\author{
Merve APSAK $^{1}$, Ahmet AKDEMIR $^{2}$ (D) Fazliye KARABORK $^{3, *}$ (D) Sakir YAZMAN $^{4}$ (i) \\ ${ }^{I}$ Graduate School of Natural and Applied Science, Necmettin Erbakan University, Konya, Turkey \\ ${ }^{2}$ Department of Aircraft Engineering,Faculty of Aviationand Space Sciences, Necmettin Erbakan University, Konya, Turkey \\ ${ }^{3}$ Department of Mechanical Engineering, Faculty of Engineering, Aksaray University, Aksaray, Turkey \\ ${ }^{4}$ Ilgin Vocational School, Selcuk University, Konya, Turkey
}

\section{Highlights}

- Mechanical and corrosive properties of stainless steel surfaces were studied.

- Epoxy nanocomposite coatings reinforced with nano Zn were applied on the steel surface.

- Instead of $\mathrm{ZnO}$ used in limited number of studies on this subject, $\mathrm{Zn}$ was used in this study.

- The effects of post curing on nanocomposites properties were investigated.

- It has been demonstrated that the applied coating improves mechanical and corrosive properties.

\begin{tabular}{l} 
Article Info \\
\hline Received:30 June 2020 \\
Accepted:23 Dec 2020 \\
Keywords \\
Nanocomposite coating \\
Postcure \\
Impact \\
Adhesion \\
Corrosion
\end{tabular}

\section{INTRODUCTION}

Stainless steels are of great interest in industrial applications because of their outstanding corrosion resistance, good mechanical properties, internal durability, ductility and good machinability. However, stainless steels are susceptible to various forms of localized corrosion such as pitting, intergranular corrosion, SCC (stress-corrosion cracking) and erosion corrosion in chloride ions rich environments similar to marine environment.

Therefore, in order to increase the service life of stainless steel substrates in an environment rich in chloride ions, additional corrosion protection means are required. Polymeric coating is one of the methods studied to improve the corrosion resistance of stainless steels. One of the important issues is to keep the mechanical properties of the surface at a good level while protecting the metal from the corrosive effects with the coating to be made. Epoxy is widely used in many engineering applications as it is an environmentally friendly polymeric material that combines several remarkable properties such as good thermal, corrosion and chemical resistance. In addition to these positive properties, the epoxy exhibits good interfacial adhesion to various metals, which encourages the search for epoxy as a coating that improves corrosion and mechanical properties for stainless steel surfaces. It was reported that, epoxy coatings also displayed

\begin{abstract}
In this study, effects of zinc nanoparticles (ZNPs) on the mechanical properties of epoxy coatings and anticorrosion behavior on the stainless steel were investigated. The nanocomposites (NCs) were obtained by adding ZNPs $(0.5,1.0,1.5 \mathrm{wt} \%)$ to epoxy resin. The first stage in this study, analysis were performed separately for samples cured at room temperature for $24 \mathrm{~h}$ and postcured $8{ }^{\circ} \mathrm{C}$ for $15 \mathrm{~h}$ in the oven. The results indicated that both postcuring and adding ZNPs caused an increase in the mechanical properties of the epoxy matrix. Tensile strength increased by $13.2 \%$ prepared with the same parameters for the second stage were coated on AISI 304 test panels and the panels were postcured in the oven. The anticorrosive performance of the coatings was studied surface preserves the best rate of $1.0 \%$ ZNPs containing epoxy composite. In addition, impact resistance, flexibilities and adhesion properties of the coating were analyzed.
\end{abstract}


better corrosion protection abilities of stainless steel than the other polymeric coating materials such as acrylic [1].

It is also reported that the corrosion protection and the mechanical properties of the polymer matrix can be positively affected by the addition of nanoparticles. Coatings containing nanoparticles such as $\mathrm{ZnO}$ [2], $\mathrm{TiO}_{2}$ [3], $\mathrm{Fe}_{2} \mathrm{O}_{3}$ [4], carbonnanotubes [5] and graphene [6], have better protection capabilities due to the homogeneous dispersion of the polymer matrix on the metallic surface.

For this purpose, it is envisaged that zinc, which is known to be used in applications for corrosion protection of metallic surfaces, can be used to increase the corrosion resistance of the epoxy coating. It is well known that, zinc is a metal frequently used in coatings as an anticorrosion pigment for metallic surfaces and the zinc provides both barrier and cathodic protection via the sacrificial effect [7]. Zinc added to the coating as a pigment is a powder of micron size and is added in large quantities for intimate contact of the particles with each other and with the metallic substrate to be protected. In this way, sufficient electrical contact ensures and the metallic substrate is protected [7]. However, the aim of this study is to investigate the protective properties of zinc in nanoscale and to a much lesser extent on stainless steel surfaces. There are some papers in the literature devoted to the study of showing the effect of epoxy coatings reinforced with zinc based materials on corrosion protection of iron and steels $[8,9]$. However, these studies focused on the effect of $\mathrm{ZnO}$, there are fewer reports about the effect of $\mathrm{Zn}$. In addition, one of the most important aims of this work is to reveal the effect of zinc reinforced epoxy coating on mechanical properties on the stainless steel surface and contribute to studies that are not sufficient in this field. As a result, further research is required to understand the effect of zinc reinforced epoxy coating on corrosion and mechanical properties of stainless steels.

In this study, nanocomposite material was prepared by adding ZNPs in different proportions $(0.5,1.0,1.5$ $\%$ by weight) to the epoxy matrix. The samples were produced from the nanocomposite material, tensile test was used to determine the mechanical properties and SEM analysis of the fracture surfaces was carried out to analyze the damage behavior. In this stage, these properties of the samples cured at room temperature were re-examined by postcuring in the oven. The prepared material was also coated on the surface of AISI 304 stainless steel test plates and subjected to corrosion test by standing in chlorinated solution in order to determine the corrosion resistance. Furthermore, in order to determine the effects of ZNPs on the curing and thermal properties of epoxy resin, and to investigate the mechanical properties of the coating; FTIR, TGA, DSC analysis and, impact and bending tests were also performed.

\section{MATERIAL METHOD}

\subsection{Materials}

The epoxy resin (diglycidyl ether of bisphenol A) and aliphatic polyamine hardener were obtained from Labkon Co. Ltd., Turkey. Zincnanoparticles (ZNPs, average particle size: 60-70 nm) was obtained from Nanografi Co. Ltd., Turkey. Stainless steel (AISI 304) plates $(160 \times 80 \times 2 \mathrm{~mm})$ were used as substrates. The steel plates $(18.35 \mathrm{wt} \% \mathrm{Cr}, 8.12 \mathrm{wt} \% \mathrm{Ni}, 2 \mathrm{wt} \% \mathrm{Mn}, 0.75 \mathrm{wt} \% \mathrm{Si}, 0.045 \mathrm{wt} \% \mathrm{P}, 0.03 \mathrm{wt} \% \mathrm{~S}, 0.07 \mathrm{wt} \%$ $\mathrm{Mo}, 0.23 \mathrm{wt} \% \mathrm{Cu}, 0.08 \mathrm{wt} \% \mathrm{C}$, Fe balance) were mechanically roughened with emery paper (grade no. 400 and 1000) and cleaned with acetone before the coating was applied.

\subsection{Preparation of Epoxy Nanocomposites and Coatings}

The experimental study was carried out in two stages. Firstly, the bulk nanocomposite was produced from the ZNPs reinforced epoxy material. At this stage, it is objected to examine the effects of the added nanoparticle ratio on the curing, thermal and mechanical properties of epoxy. In addition, these properties of the samples cured at room temperature were re-examined by postcuring in the oven. In the second stage, the coating was applied to the surface of stainless steel test plates with NCs prepared with the same parameters. The coated samples; adhesion, elasticity and corrosion resistance of the coating were analyzed. In the following, the preparation of the composite material, the application of the coating and the tests and analyzes performed are explained in detail. 
Epoxy based NCs containing ZNPs were prepared using solution mixing method for the providing a homogeneous dispersion of ZNPs in epoxy resin at ratios of $0.5,1.0$ and $1.5 \mathrm{wt} \%$ by the following procedures. Ultrasonication was carried out for four cycles (of 10 min each one) in an ice bath to obtain a more homogeneous nanoparticle dispersion after the nanoparticles were added to the epoxy. Then the mixtures were kept in a vacuum oven (at -0.75 bar for $10 \mathrm{~min}$ ) to eliminate any trapped gases. A polyamide hardener was added to the epoxy resin $(2.5: 1 \mathrm{w} / \mathrm{w})$ and the mixture was stirred mechanically, and then dumbbell shaped tensile bars are molded (five specimens from each mixture) in accordance with the ASTM D638-95 test standards. In the final stage, the NCs were cured at room temperature for $24 \mathrm{~h}$ and postcured at $80{ }^{\circ} \mathrm{C}$ for $15 \mathrm{~h}$.

The coating was applied on the stainless steel substrate using a film applicator (Figure 1). The coated steel plates were cured at room temperature for $24 \mathrm{~h}$ and then postcured at $80^{\circ} \mathrm{C}$ for $15 \mathrm{~h}$. The average dry film thickness was obtained to be in the range of $60 \pm 10 \mu \mathrm{m}$. The thickness value was obtained by averaging ten readings made from random places of the coating.

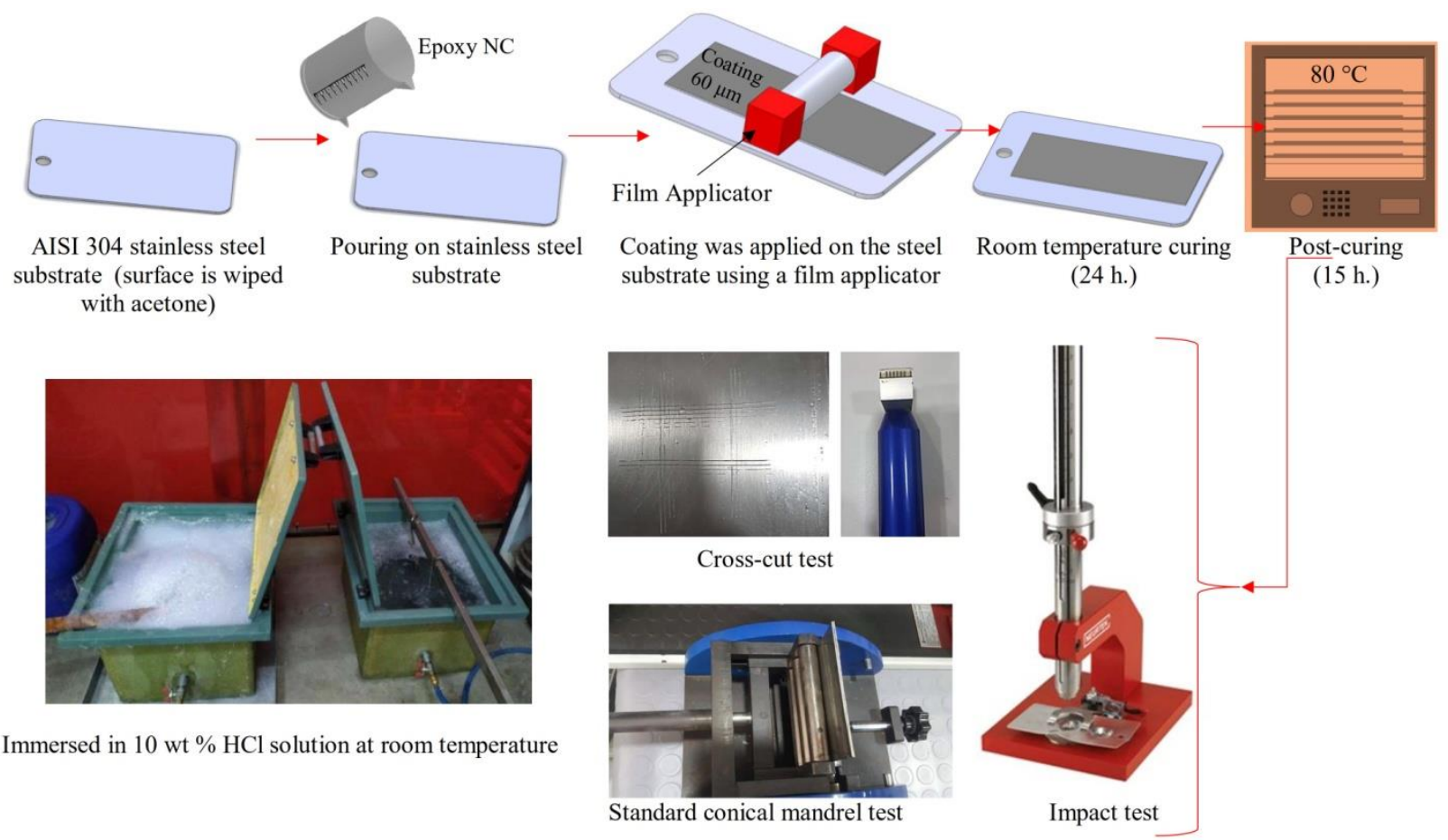

Figure 1. Application and characterization of the nanocomposite coatings

\subsection{Characterization}

Tensile propertiesof the epoxy NCs were measured with Shimadzu AGS-X tensile testing machine according to ASTM D 638-14 at room temperature. Testing speed was $2 \mathrm{~mm} \mathrm{~min}^{-1}$. At least five samples for each composition were examined, and the average value was reported.

The interaction between the the nanoparticles and epoxy matrix was analyzed with Thermo Scientific Nicolet IS5 FTIR spectrometer in the wavelength range of 500-4000 $\mathrm{cm}^{-1}$. Thermogravimetric analysis (TGA) was performed using $10 \mathrm{mg}$ sample from ambient temperature to $800{ }^{\circ} \mathrm{C}$ with a heating rate of 10 ${ }^{\circ} \mathrm{C} \mathrm{min}{ }^{-1}$ under nitrogen atmosphere. In order to determine the effects of ZNPs and postcuring on the thermal stability of the NCs. The effects of nanoparticles incorporated in epoxy resin on curing behavior were performed by differential scanning calorimetry analysis (DSC, Setaram - LabsysEvo) with a heating rate of $10{ }^{\circ} \mathrm{C} \mathrm{min}-1$ under increasing temperature conditions from $40^{\circ} \mathrm{C}$ to $350{ }^{\circ} \mathrm{C}$. The analysis was performed using $10 \mathrm{mg}$ sample under a nitrogen flow rate of $50 \mathrm{~mL} \mathrm{~min}^{-1}$. The morphology of the tensile fracture surface and the dispersion of nanoparticles in the epoxy matrix were studied using a Hitachi-SU 1510 scanning electron microscope (SEM). 
Various tests were carried out on the test plates in order to determine the physical and mechanical properties of the coating (Figure 1). The cross-cut test (ASTM D 3359) was performed to examine the adhesion strength of the coating to the substrate. In this method, the coating was cut using a tool to form a grid on the surface which completely penetrates the surface. The standard pressure sensitive tape was applied to the surface and removed. Adhesion was graded according to the amount of coating removed from the surface; 0B (> $65 \%$ coating removal), 1B (35-65\%), 2B (15-35\%), 3B (5-15\%), 4B $(<5 \%)$ and 5B $(0$ $\%$, or none). Impact tests were carried out with Neurtek Impact Tester using the standard test method ASTM D 2794. In this test, a hemispherical indenter of a standard weight $(0.9 \mathrm{~kg})$ is dropped onto the coated plates and the drop height causing mechanical damage to the coating is recorded. The impact test was performed starting at a height of $40 \mathrm{~cm}$ and increasing the height by $10 \mathrm{~cm}$ at each measurement. The standard cylindrical mandrel test was applied to the coated panels for evaluation of crack resistance according to ASTM D 4145. The test was performed by bending the coated panels around the mandrel. It was examined whether or not the coating had a crack in the bending area.

The corrosion protection properties of the coated specimens were evaluated using to immersion test. For this purpose, coatings with $\mathrm{x}$-scratches $(2 \mathrm{~mm}$ width and $4 \mathrm{~cm}$ length) were immersed in 10 volume $\% \mathrm{HCl}$ solution at room temperature and subjected to $300 \mathrm{~h}$ corrosion test. At the end of the test, the blistering degree was analyzed according to ASTM D-714-87/00 (TS 9260 EN ISO 4628). The method categorizes the blisters to the groups considering their sizes described by numbers 2 (the largest), 4, 6, and 8 (the smallest). The information on the frequency of blister existence is attached to the blister size number. The greatest density of blisters is marked as D (dense), whereas less dense blister is marked as MD (medium dense), $\mathrm{M}$ (medium) and $\mathrm{F}$ (few). The degree of blisters is formed from the lightest to the heaviest, as follows: $8 \mathrm{~F}-6 \mathrm{~F}-4 \mathrm{~F}-2 \mathrm{~F}-8 \mathrm{M}-6 \mathrm{M}-4 \mathrm{M}-2 \mathrm{M}-8 \mathrm{MD}-6 \mathrm{MD}-4 \mathrm{MD}-2 \mathrm{MD}-8 \mathrm{D}-6 \mathrm{D}-4 \mathrm{D}-2 \mathrm{D}$. In addition, coating delamination from the scratches was analyzed.

\section{THE RESEARCH FINDINGS AND DISCUSSION}

\subsection{Tensile Properties of Nanocomposites}

The tensile strength, toughness and elongation at break mean values are given against the ZNPs contents in Figure 2 for postcured and untreated (non postcured) specimens. In this study, it was observed that both postcuring and ZNPs caused an increase in the mechanical properties of the epoxy matrix. The effect of postcuring was clearly observed with an increase of $118.2 \%$ in the tensile strength of neatepoxy.The tensile strength, toughness and elongation at break values of the ZNPs reinforced postcured samples are increased with the incorporation of ZNPs up to $1.0 \mathrm{wt} \%$ (Figure 2). With an increase of reinforcement ratio, these values showed a decreasing tendency, but all values are higher than neat epoxy. Likewise, it is seen that there is an increase in tensile strength, toughness and elongation at break values in the untreatedsamples, but the highest increase was in samples with $0.5 \% \mathrm{Zn}$ reinforced (Figure 2). The effect of ZNPs on the mechanical properties was more pronounced in the untreated samples compared to the postcured samples and although less nanoparticles $(0.5 \%)$ were added to the untreated samples, better properties were obtained. In postcured samples, it is seen that postcuring is more effective on mechanical properties than ZNPs. 


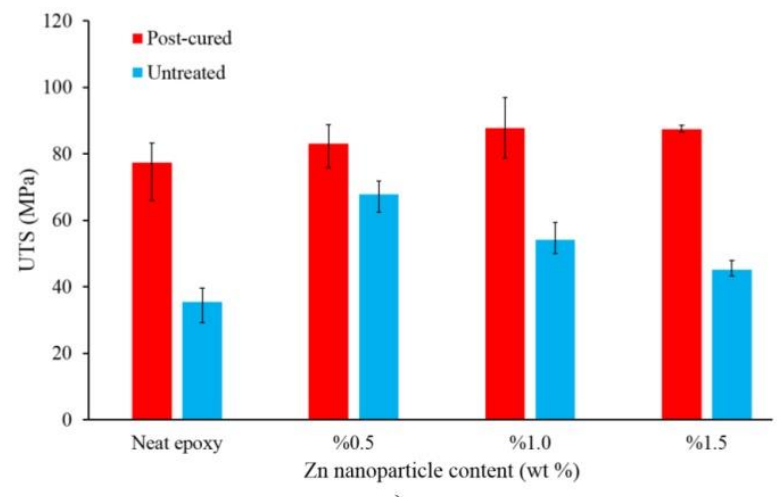

a)

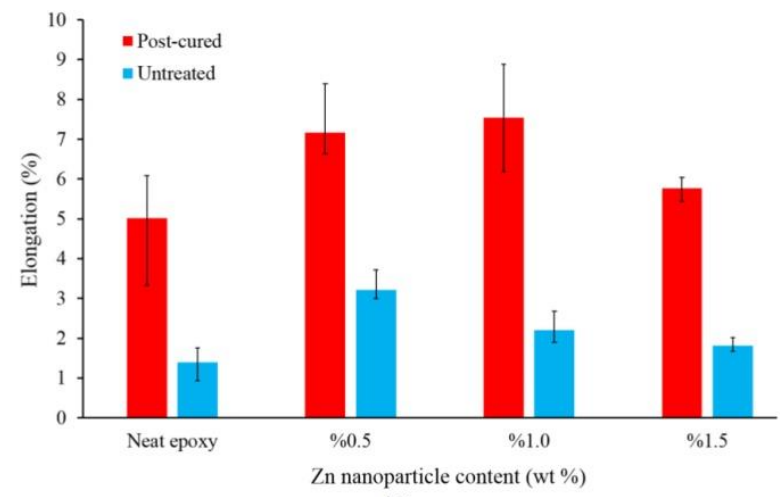

b)

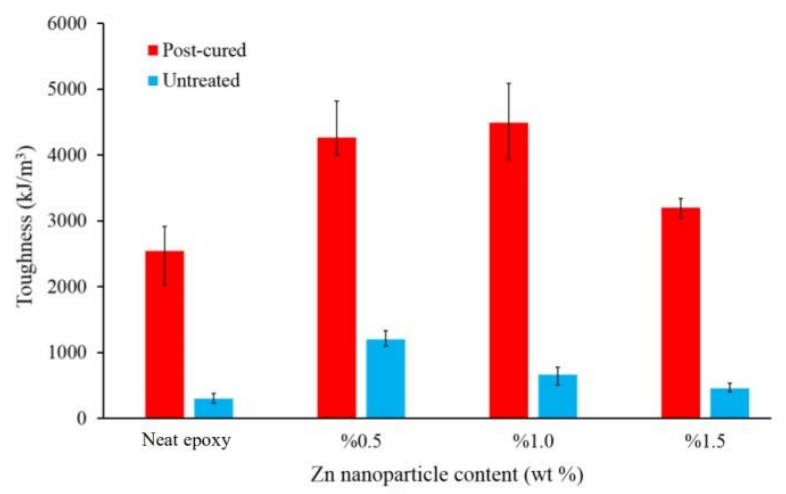

c)

Figure 2. Tensile properties of the postcured and untreated NCs with varying reinforcement ratios. a) UTS, b) elongation and c) toughness

The effects of the postcuring and nanoparticle on the deformation regions of the tensile curves of the nanocomposite are shown in Figure 3. Tensile curves divided into three different regions; elastic deformation, uniform plastic deformation and nonuniform deformation. It is seen that, the postcuring causes more plastic deformation before breaking for the ZNPs reinforced and non-reinforced samples which affects the mechanical properties (Figure 3). 

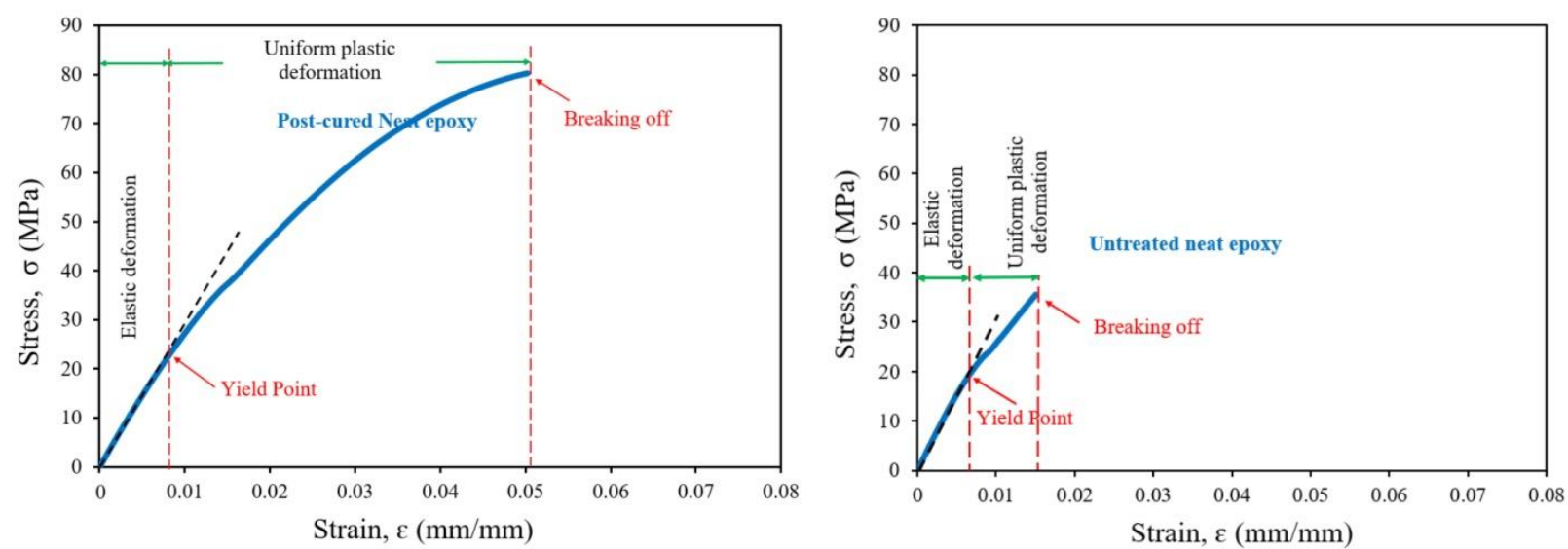

a)

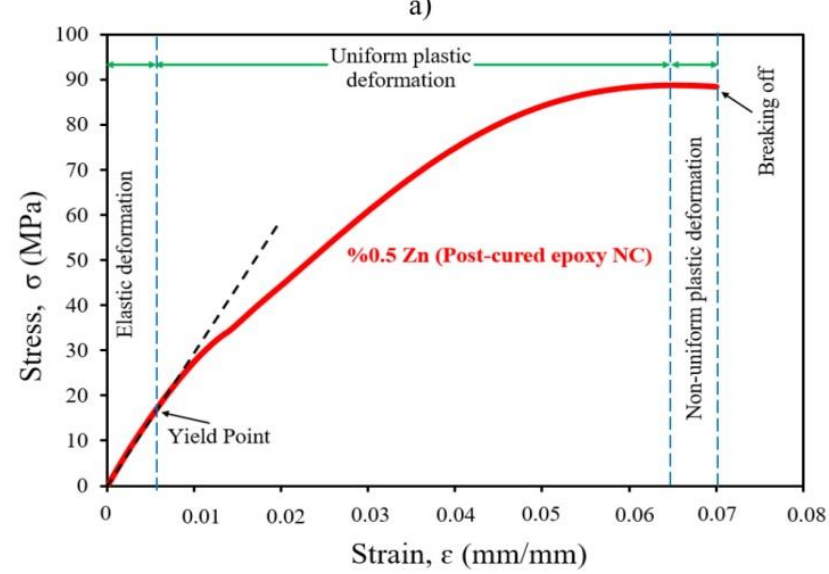

c)

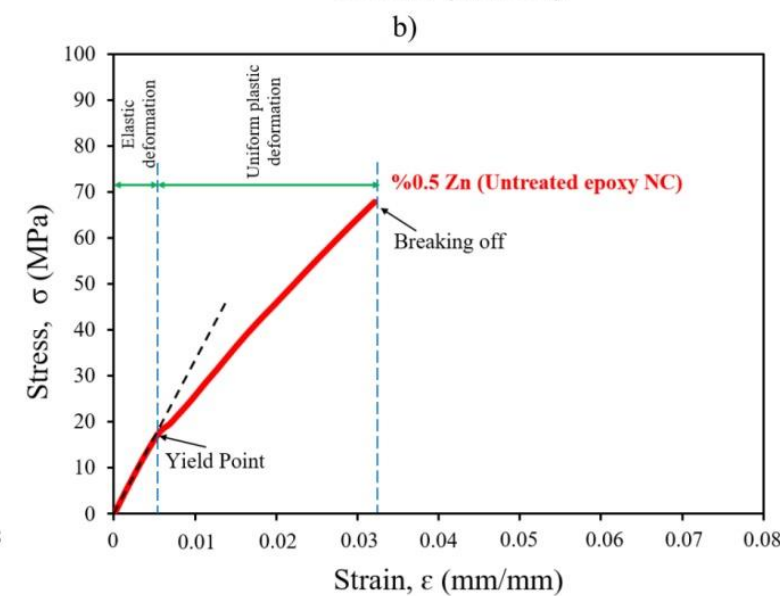

d)

Figure 3. Tensile curves of the neat epoxy and epoxy NCs a) postcured neat epoxy, b) untreated neat epoxy, c) postcured epoxy NC (0.5 wt. \%) and d) untreated epoxy NC (0.5 wt. \%)

All these results suggest that postcuring and nanoparticle addition has different strengthening mechanisms on the epoxy matrix. The increase in the mechanical properties obtained by postcuring was achieved by the formation of the covalent bonds in the unreacted parts of the matrix causing an increase in the bond strength. Incorporating ZNPs into the epoxy NCs contributed to increase the strength by limiting the free movement of polymer molecule chains. The increase in the mechanical properties of the untreated specimens was achieved by homogenous dispersing of the nanoparticles (Figure 4), resulting in a crosslinking between the free molecule chains with a postcure-like effect. It has been observed that the mechanical properties deteriorate with the increase in the amount of nanoparticles, which is due to the agglomeration of the nanoparticles in the matrix. Agglomerated nanoparticles behave like macroscopic impurities that reduce the nano effect, which tends to reduce the intermolecular Van der Waals forces resulting in a weaker crosslinked polymer. 


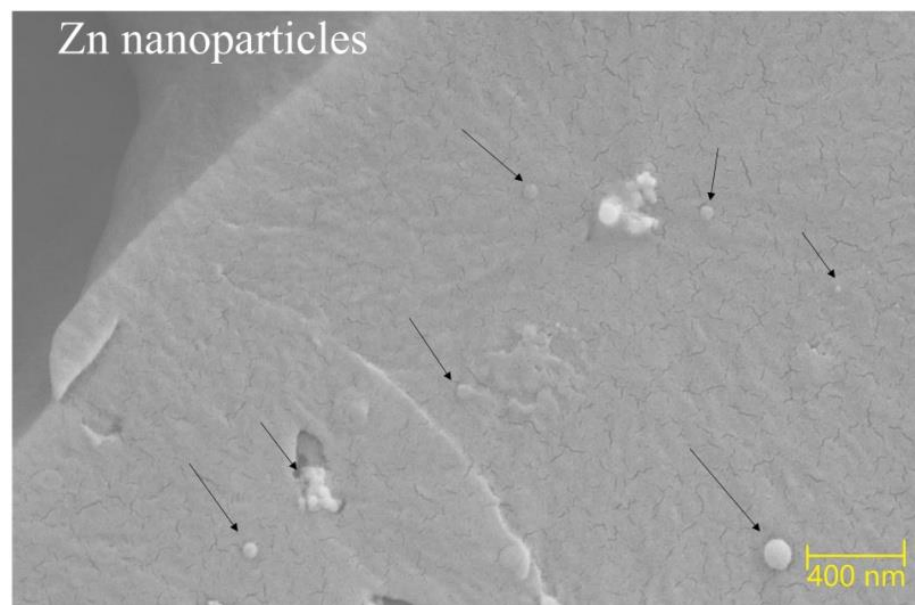

Figure 4. SEM micrographs of the ZNPs/epoxy coating surface

\subsection{SEM Analysis of the Fracture Surfaces}

The morphologies of the fractured surfaces of the postcured neat epoxy and its nanocomposites after the tensile tests are given in Figure 5. Three different fracture regions are observed on the fracture surfaces of thermoset polymers; mirror, mist and hackle. It has been observed that the formation of these regions change depending on the amount and distribution of nanoparticles. When the mist regions are examined, it is seen that the crack lengths in the NC reinforced with $1.0 \%$ ZNPs are longer than the other NCs (Figure 5). In addition, there are differences in hackle zones of the samples. In the neat epoxy and NC reinforced with $0.5 \%$ ZNPs, the brittle fracture surfaces in the plastic deformation zone are wider than in the NC reinforced with $1.0 \%$ ZNPs, whereas in this NC these zones are smaller, more frequent and densely distributed. In this case, it can be said that this region absorbs more energy in the NC reinforced with 1.0 $\%$ ZNPs than in the neat epoxy and NC reinforced with $0.5 \%$ ZNPs. In other words, NC reinforced with $1.0 \%$ ZNPs has a high surface roughness, which is predicted to delay the crack propagation because it will break by requiring more energy for fracture. This result is compared with the results of tensile test, this characteristic morphology was also evaluated as the reason for the achieved enhancements in the tensile strength, static toughness and also impact strength.

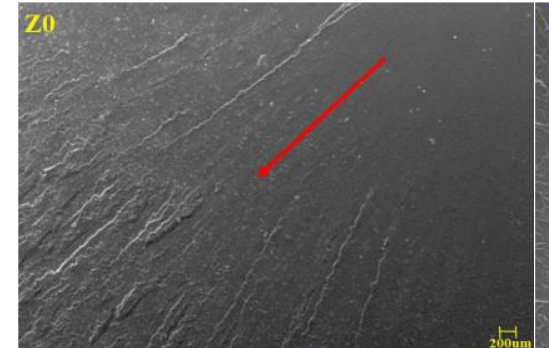

a)

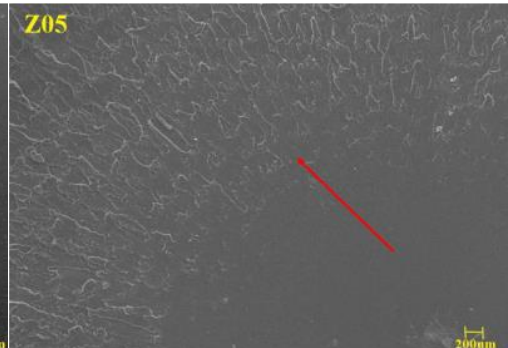

b)

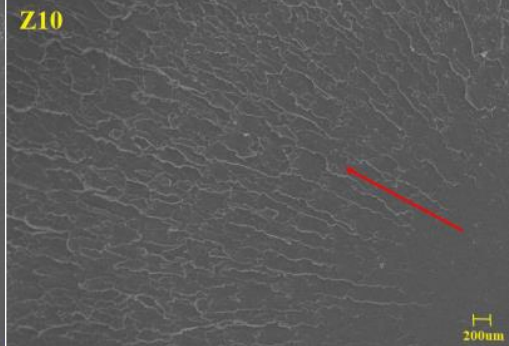

c)

Figure 5. SEM micrographs of the fracture surfaces of (a) neat epoxy, (b) NC (0.5 wt. \%) and (c) NC (1.0 wt. \%) (directions of crack propagation were indicated by red arrows)

The untreated neat epoxy and its NCs exhibited partially rough surfaces with the addition of ZNPs, but as previously mentioned, ZNPs incorporation was not as effective on mechanical properties as postcuring (Figure 3).

Different toughness mechanisms are observed particle modified epoxies with due to the shape of the particles. Generally, the most effective toughness enhancing mechanisms for the fiber like nanoparticles are the particle bridging and pull-out mechanisms, and the crack pinning and bowing mechanisms for the 
spherical nanoparticles. According to the crack pining theory, when a crack encounters rigid particles, the particles can act as pin points and the crack is pinned [10]. The crack tends to bowing between the particles and to creating secondary cracks. The bowed secondary cracks have more stored elastic energy than straight unbowed one. Therefore, more energy is required for crack propagation, resulting in increased fracture toughness of the NCs [10]. In addition, enhancing the efficiency of pinning is depend the good particle matrix bonding. Microstructures with river-like lines, possibly caused by crack compression and blocking effects of nanoparticles, are characteristic of this mechanism. This characteristic feature is visible on the fracture surfaces of the Zn reinforced NCs (Figure $6 \mathrm{a}, \mathrm{b}$ ). It has been also observed that the fracture surfaces have crack propagation mechanisms, such as crack branching and deflection, which require more energy for crack propagation (Figure $6 \mathrm{c}, \mathrm{d}$ ). Observing the mechanisms more intensely on the fracture surface of the epoxy NC reinforced with $1.0 \%$ ZNPs supports the tensile test results, the highest tensile strength and toughness values were measured from this sample.

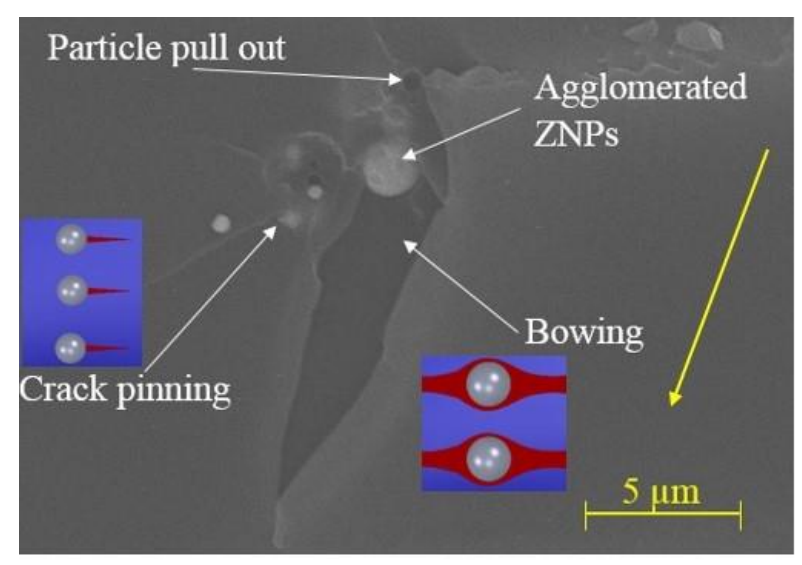

a)

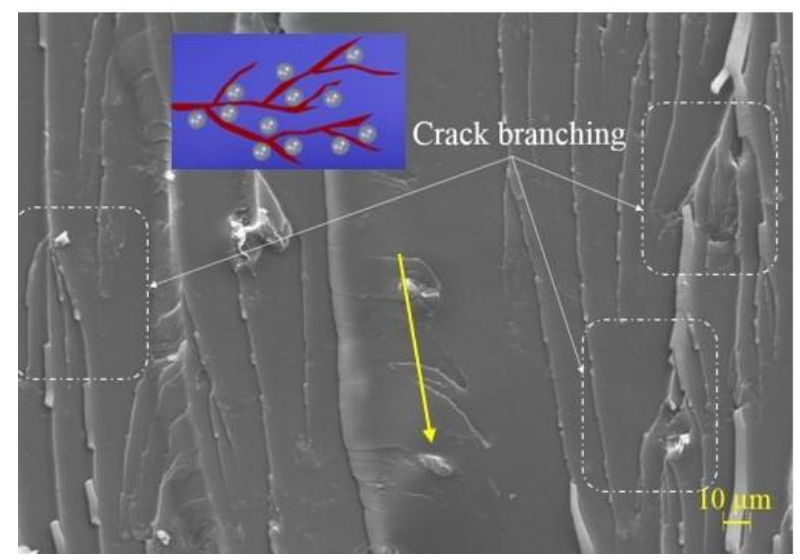

c)

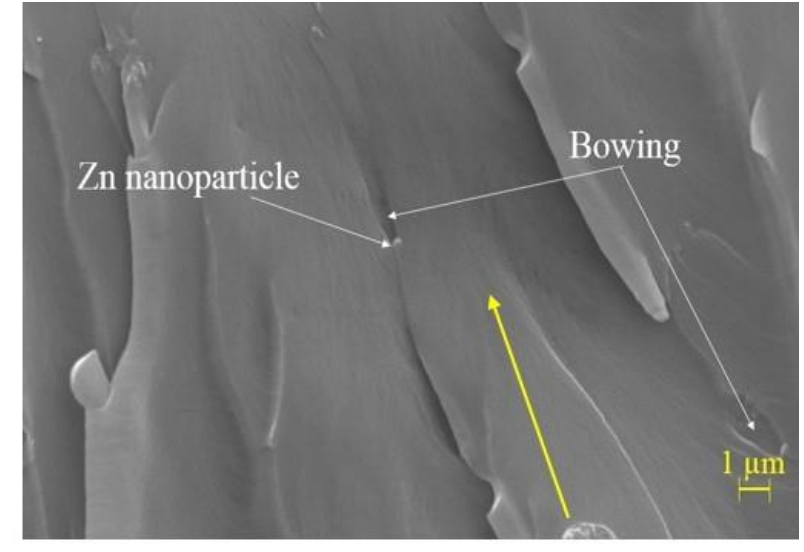

b)

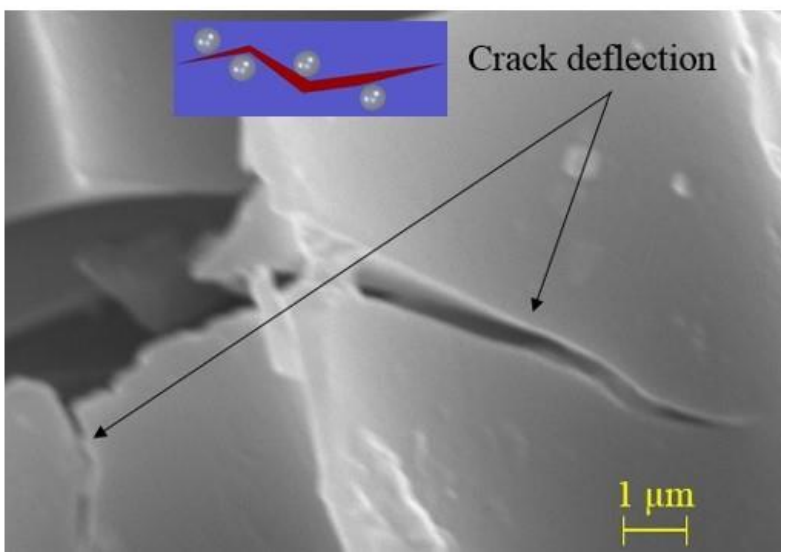

d)

Figure 6. SEM micrographs of the different toughening and crack propagation mechanisms: a,b) crack pinning and bowing, $c$ ) crack branching d) crack deflection (direction of deformation were indicated by yellow arrows)

\subsection{TG Analysis of Nanocomposites}

Table 1 shows the test results obtained by TGA analysis. Incorporated ZNPs did not importantly affect thermal stability of the epoxy matrix. But degradation temperatures $\left(\mathrm{T}_{\mathrm{d} 50}\right)$ at $50 \%$ weight loss of all reinforced epoxy are slightly decreased as compared to neat epoxy. However, effect of postcuring on thermal stability was more pronounced than the addition of ZNPs. Experimental results were analyzed, it was observed that the thermal stability of the postcured samples was generally higher as compared to untreated samples (Table 1). The degradation temperature of the polymer composites depends on both the chemical structure and the crosslinking density. In addition, the char yield of untreated neat epoxy is 17.24 
$\mathrm{wt} \%$ and that of postcured epoxy is $22.84 \mathrm{wt} \%$ at $800{ }^{\circ} \mathrm{C}$. In this study, crosslinking density of the composites increased by the postcuring and this highly crosslinked network has high thermal stability. On the other hand, epoxy NCs are degraded at single step, instead of two-step manner. This trend indicates the good interaction between the inorganic particles and organic matrix.

Table 1. $T_{d 50}$, Char yield at $800^{\circ} \mathrm{C}$ and Tgof neat epoxy and $\mathrm{Zn}$ added NCs

\begin{tabular}{|c|c|c|c|c|c|c|}
\hline \multirow{2}{*}{$\begin{array}{c}\text { Znwt } \\
\%\end{array}$} & \multicolumn{2}{|c|}{$\mathrm{T}_{\mathrm{d} 50}\left({ }^{\circ} \mathrm{C}\right)$} & \multicolumn{2}{c|}{ Charyield at $800^{\circ} \mathrm{C}(\%)$} & \multicolumn{2}{c|}{$\operatorname{Tg}\left({ }^{\circ} \mathrm{C}\right)$} \\
\cline { 2 - 7 } & Untreated & Postcured & Untreated & Postcured & Untreated & Postcured \\
\hline 0 & 370.11 & 373.88 & 17.24 & 22.84 & 88.84 & 90.48 \\
\hline 0.5 & 363.39 & 373.15 & 16.75 & 25.40 & 86.17 & 89.21 \\
\hline 1.0 & 361.42 & 364.51 & 17.62 & 22.25 & 89.56 & 89.17 \\
\hline 1.5 & 363.98 & 366.35 & 20.72 & 26.67 & 88.33 & 98.31 \\
\hline
\end{tabular}

\subsection{DSC Analysis of Nanocomposites}

Table 1 also shows the change in Tg for the neat epoxy and epoxy NCs depending on postcuring. Tg of a polymeric composites changes for a kind of reasons, including crosslinking density, molecular weight, interfacial area and, size and amount of nanoparticles. It can be observed that the postcuring leads to an increase in the Tg measured during the heating. This phenomenon is due to the increase of the crosslinking rate of the composite. With the addition of ZNPs, a slight decrease in Tg was observed generally for all samples.

\subsection{FTIR Analysis}

Figure 7a and $\mathrm{b}$ show the FTIR spectrum of the postcured and untreated epoxy composites reinforced with ZNPs. The absorption bands corresponding to $\mathrm{C}-\mathrm{H}$ band $\left(2878-2977 \mathrm{~cm}^{-1}\right)$, epoxide ring $\left(826 \mathrm{~cm}^{-1}\right), \mathrm{N}-\mathrm{H}$ band of primary amines $\left(1590-1610 \mathrm{~cm}^{-1}\right), \mathrm{O}-\mathrm{H}$ groups $\left(3400 \mathrm{~cm}^{-1}\right), \mathrm{C}-\mathrm{N}$ band $\left(1036-1100 \mathrm{~cm}^{-1}\right)$ and epoxy ring $\left(836 \mathrm{~cm}^{-1}\right)$ are characterized in Figure 7 . The change in intensity of the $(\mathrm{O}-\mathrm{H})$ band can be considered as a sign of the effect of the presence of ZNPs on the curing reaction rate. Figure 7 shows that the intensity of the epoxy containing nanoparticle $(\mathrm{O}-\mathrm{H})$ band is higher than that of neat epoxy, which means that the curing reaction rate is reduced in the presence of ZNPs. There are two reasons for this result; the first one, the presence of nanoparticles increases the viscosity which causes lower chain mobility of the resin and hardener, and the second one, the steric hindrance effect of nanoparticle reduces the degree of reaction of functional groups of the resin and hardener [11]. These reasons are also other possible causes of the decrease in the mechanical properties of nanocomposites due to the increased amount of nanoparticles.

On the other hand, slight shifts in the band frequencies were observed after addition of nanoparticles. The effect of ZNPs on the shifts in the peaks was more pronounced in the untreated samples compared to the postcured samples as with the mechanical properties of the nanocomposite. The shifts in the peaks are an evidence of the nanoparticle/matrix interfacial interaction but this interaction is more physical than chemical due to no new peaks in the spectrum [12]. 


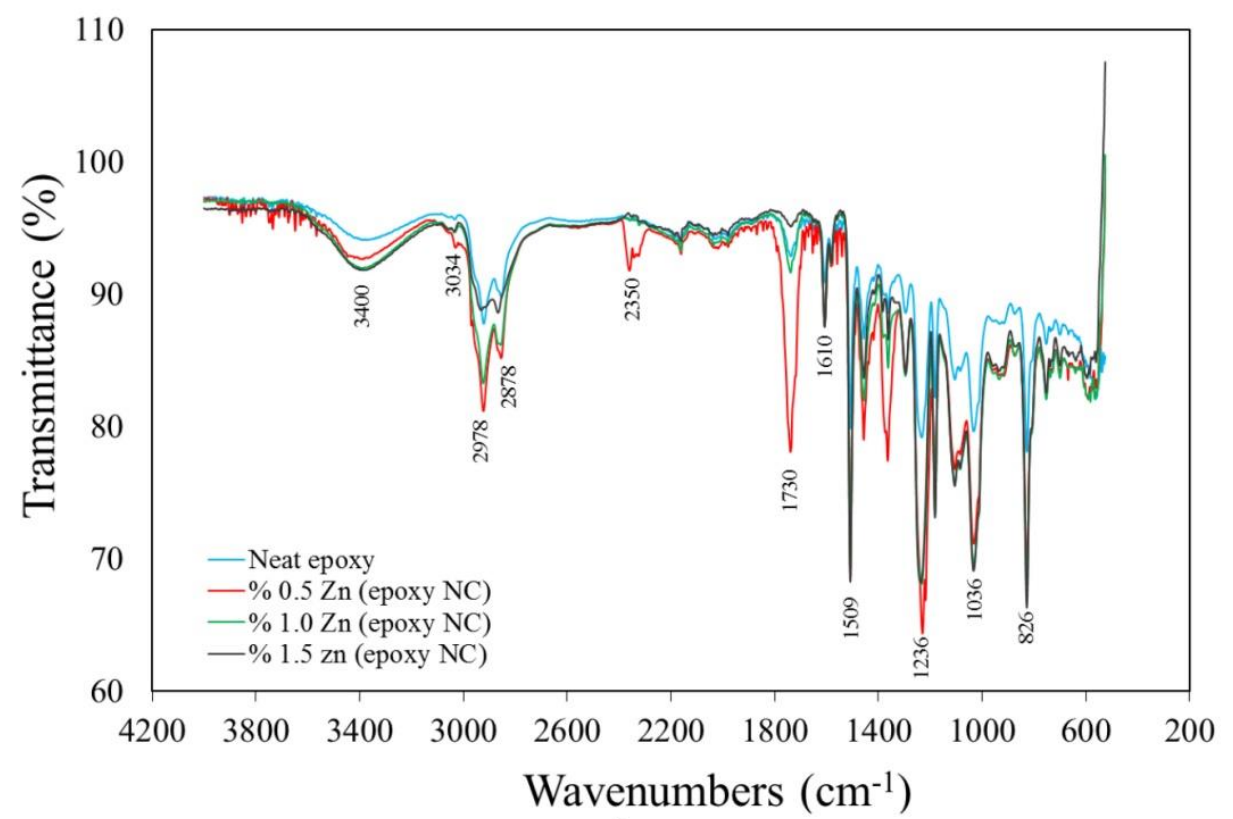

a)

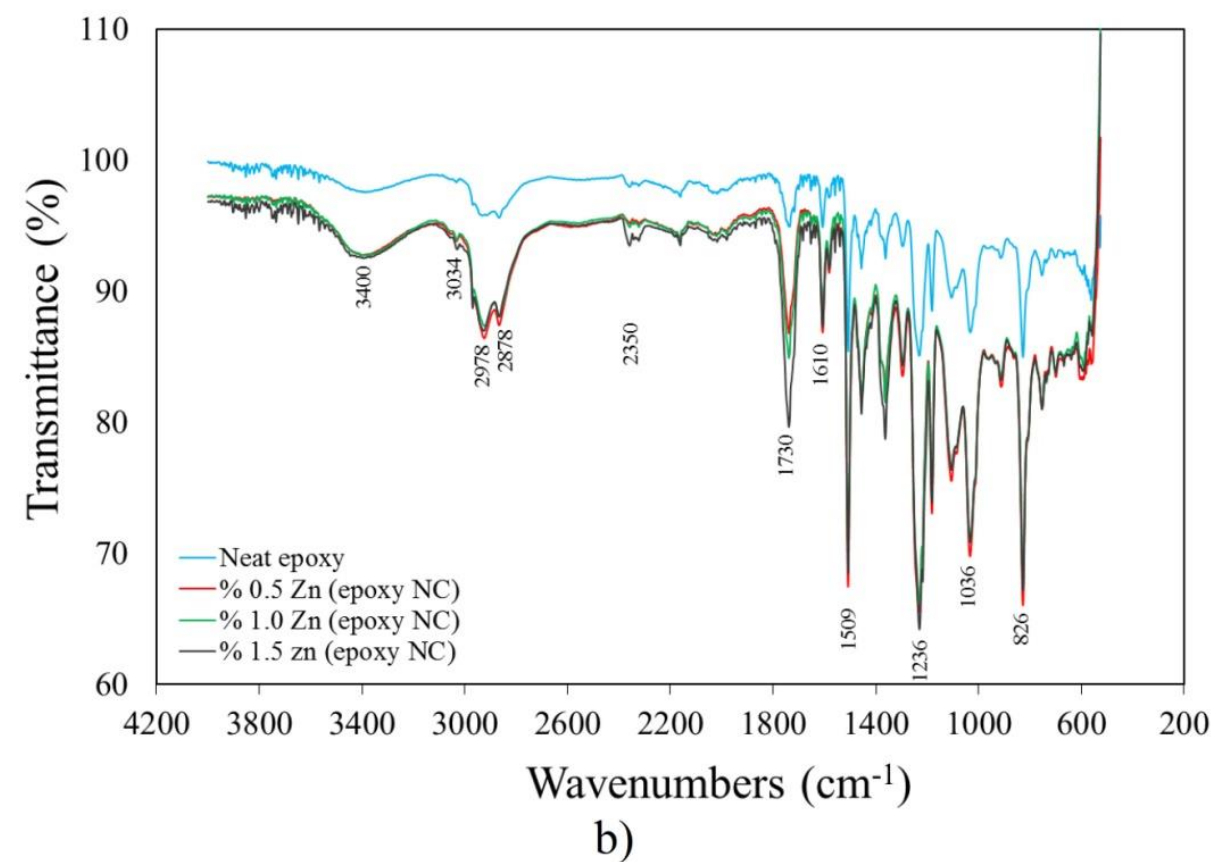

Figure 7. FTIR spectra of the neat epoxy and Zn added NCs a) untreated b) postcured

\subsection{Physical and Mechanical Properties of Coatings}

As a result of the characterization of epoxy bulk composite, it was determined that the mechanical properties of the postcured specimens were better than the untreated samples. Therefore, in this study, postcuring was preferred after coating. In this preference, one phenomena are effective, excepting of the better mechanical properties; the high Tg value, which is a result of the increase in crosslink density obtained from postcured composites. Because, it is generally accepted that, a high Tg (or crosslink density) results in a lower permeation rate, given that there is lower free volume or space in the polymer for molecules like water vapor to permeate through.

Mechanical and physical properties of the coatings were determined with cross-cut, bending, impact and corrosion tests, and the results are given in Table 2. As a result of the cross-cut test, there were no paint 
flakes separated from the all substrates and the traces on the samples were evaluated as 5B class (Table 2) which indicates satisfactory adhesion. The impact resistance test results given in Table 2 show that the neat epoxy coatings, and epoxy coatings reinforced with $0.5 \%$ and $1.0 \%$ ZNPs were damaged at a height of 50,60 and $70 \mathrm{~cm}$, respectively. However, the first damage was observed at a height of $90 \mathrm{~cm}$ in the epoxy coating reinforced with $1.5 \%$ ZNPs. It can be said that, interaction of nanoparticles and epoxy at higher ZNP content, is responsible for increased impact resistance. Similar results have been suggested by the researchers and it is stated that impact resistance, which is one of the weak properties of epoxy coatings, can be increased by adding nanoparticles to the matrix [13]. According to the bending test result, no cracking or tearing was observed in any sample, including neat epoxy (Table 2). It has been interpreted that this is due to the fact that the coating has very good adhesion to the substrate surface and has sufficient flexibility.

Table 2. Coatings properties

\begin{tabular}{|c|c|c|c|}
\hline $\begin{array}{c}\mathrm{Zn} \\
(\mathrm{wt} \%)\end{array}$ & Cross-cut test & $\begin{array}{c}\text { Cylindrical } \\
\text { mandrel test }\end{array}$ & $\begin{array}{c}\text { Impact test } \\
(\mathrm{cm})\end{array}$ \\
\hline 0 & 5B & Not cracked & 50 \\
\hline 0.5 & $5 \mathrm{~B}$ & Not cracked & 60 \\
\hline 1.0 & 5B & Not cracked & 70 \\
\hline 1.5 & 5B & Not cracked & 90 \\
\hline
\end{tabular}

\subsection{Immersion Test}

The aspects of the sample surfaces after the immersion tests are shown in Figure 8. In order to interpret the amount of corrosion, the blistering degree on the surfaces and degradation of the coating was examined. Since the true extent of degradation of the coating does not appear before removal of the coating, the delaminated distance was evaluated after removal of the coating from the delaminated region.

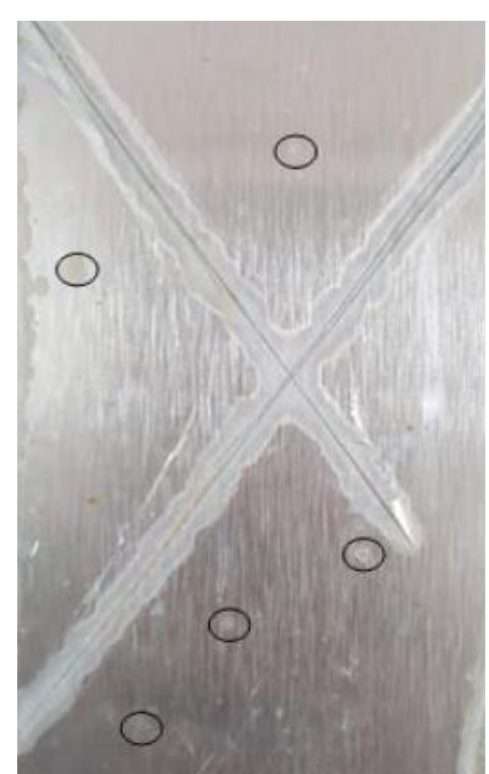

a)

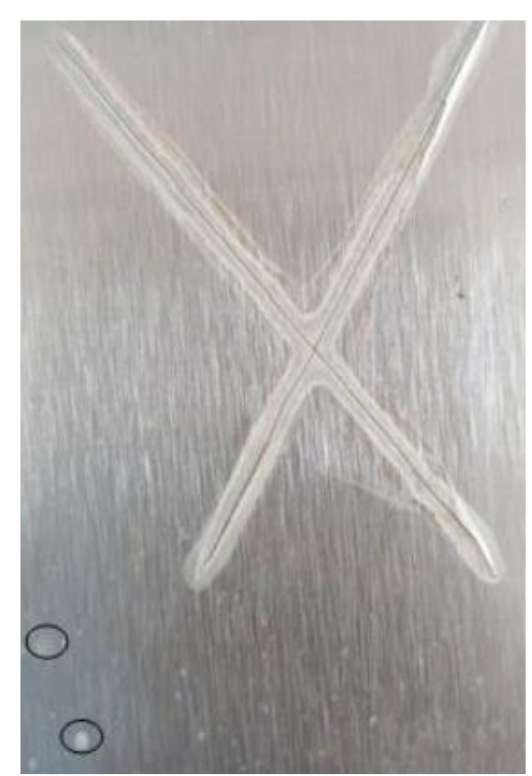

b)

Figure 8. The surface aspect of the samples after exposing to the HCI solution for 300 h. (a) neat epoxy and (b) epoxy NC (1.0 wt\% $\mathrm{Zn})$

Blistering degrees of the samples after $300 \mathrm{~h}$ immersion in HCI were obtained as follows; $4 \mathrm{M}(0 \mathrm{wt} \% \mathrm{Zn})$, $6 \mathrm{~F}(0.5 \mathrm{wt} \% \mathrm{Zn}), 8 \mathrm{~F}(1.0 \mathrm{wt} \% \mathrm{Zn}), 6 \mathrm{M}(1.5 \mathrm{wt} \% \mathrm{Zn})$. In this study, blister formation decreased with 
increasing reinforcement ratio and the best result was obtained from the epoxy coating reinforced with 1.0 $\%$ ZNPs. Researchers have suggested that, a single nanoparticle (particle size of less than $100 \mathrm{~nm}$ ) could reduce the number of defects in the coating matrix by filling the pores which are generated during the curing process, thereby effectively improving the barrier performance of the coating. In this way, they can lead to less blister formation by reducing the diffusion rate of electrolyte into the coating [14]. On the other hand, an increase in blister formation was observed by increasing ZNPs loading beyond an optimum loading of $1.0 \mathrm{wt} \%$. The increased amount of ZNPs in the coating matrix cause to the agglomeration and the formation of coating defects resulting from such agglomeration. Coating defects caused by agglomeration increases the possibility of active site formation, thus decreasing corrosion resistance.

In this study, after exposure for $300 \mathrm{~h}$ to HCI solution, all coatings showed detachment around the $\mathrm{x}$ scratches, but it was observed that the delaminated distance from scratches was lower in the epoxy coating reinforced with $1.0 \%$ ZNPs than the other coatings (Figure 8). When the coating is exposed to aggressive ions, the adhesion between the coating and the metal surface is adversely affected and delamination occurs. The delamination behavior depends on the degree of electrolyte diffusion into the coating. The use of the nanocomposite coating on the metal substrate not only improves the adhesion of the coating to the metal substrate, but also acts as a good barrier against corrosive materials when it reaches the polymeric-metallic substrate interface. This study demonstrated that epoxy coatings containing appropriate proportions of ZNPs are effective in corrosion protection of stainless steel surfaces. This improvement in protection efficiencies can be attributed both to the cathodic protection property of zinc and to the great barrier property of nanoparticles. The addition of nanoparticles to polymeric coatings provides a tortuous diffusion path for corrosive agents to reach the substrate, resulting in a lower corrosion rate and better corrosion resistance.

\section{RESULTS}

In this study, properties of nano $\mathrm{Zn}$ reinforced epoxy both as a composite material and as coating applied to the stainless steel surface were investigated, the following conclusions were reached:

- Postcuring and ZNPs caused an increase in the mechanical properties of the epoxy matrix. The best results were obtained from the presence of $1.0 \% \mathrm{Zn}$ for postcured $\mathrm{NC}$ and $0.5 \% \mathrm{Zn}$ for untreated NC, and UTS increased by $13.2 \%$ and $90.2 \%$, respectively. The experimental results show that postcuring and nanoparticle addition have different strengthening mechanisms.

- In the analysis of fracture surfaces of the postcured samples, it was observed that the epoxy NC reinforced with $0.5 \% \mathrm{Zn}$ had a high surface roughness, which could be interpreted as an indication that more energy was required for fracture.

- The effect of postcuring on thermal stability and the glass transition temperature were more pronounced than the addition of ZNPs. These phenomena are due to the increase of the crosslinking rate of the NCs.

- The curing reaction rate was observed to be slightly reduced in the presence of ZNPs by FTIR analysis.

- As a result of the examination of the properties of the postcured coating applied to the stainless steel surface, it was observed that there is no coating removal and no cracking in all samples, which is indicative of the adhesion and elastic properties of the coating, respectively. Impact resistance increased with increasing reinforcement ratio and the best result was obtained from the addition of $1.5 \% \mathrm{Zn}(80 \%)$.

- As a result of the immersion test, the lowest blister formation and also lesspaint removal rate around the scratches were observed in the epoxy coated sample reinforced with $1.0 \% \mathrm{Zn}$.

- This study demonstrated that epoxy coatings containing appropriate proportions of ZNPs exhibit remarkable barrier properties in corrosion protection without deteriorating the physical and mechanical properties of the coating and that the coating reduces pitting corrosion tendency by reducing blistering in a chemical aqueous solution containing chloride $\left(\mathrm{CI}^{-}\right)$ions such as $\mathrm{HCl}$ or $\mathrm{NaCl}$. 


\section{ACKNOWLEDGEMENT}

This study was supported by Necmettin Erbakan University Scientific Research Projects Coordination Unit (Project Number: 191316001).

\section{CONFLICTS OF INTEREST}

No conflict of interest was declared by the authors.

\section{REFERENCES}

[1] Iliopoulosa, I., Karampekiosa, A., Pandisa, P. K., Vourdasa, N., Jouharab, H., Tassoub, S., Stathopoulosa, V. N., "Evaluation of organic coatings for corrosion protection of condensing economizers", Procedia Structural Integrity, 10: 295-302, (2018).

[2] Mobin, M., Aslam, J., Alam, R., "Corrosion protection of poly(aniline-co-N-ethylaniline)/ZnO nanocomposite coating on mild steel”, Arabian Journal for Science and Engineering, 42: 209-224, (2017).

[3] Abaci, S., Nessark, B., "Characterization and corrosion protection properties of composite material $\left(\mathrm{PANI}+\mathrm{TiO}_{2}\right)$ coatings on A304 stainless steel", Journal of Coatings Technology and Research, 12: 107-120, (2015).

[4] Shaik M. R., Alam M., Alandis N. M., "Development of sustainable resource based poly(urethaneetheramide) $/ \mathrm{Fe}_{2} \mathrm{O}_{3}$ nanocomposite as anticorrosive coating materials", Journal of Polymer Engineering, 35(9): 905-916, (2015).

[5] Khun, N. W., RinconTroconis, B. C., Frankel, G. S., "Effects of carbonnanotube content on adhesion strength and wear and corrosion resistance of epoxy composite coatings on AA2024- T3", Progress in Organic Coatings, 77: 72-80, (2014).

[6] Ozcan, U. E., Karabork, F., Yazman, S., Akdemir, A., "Effect of Silica/Graphene Nanohybrid Particles on the Mechanical Properties of Epoxy Coatings", Arabian Journal for Science and Engineering, 44: 5723-5731, (2019).

[7] Shirehjini, F.T., Danaee, I., Eskandari, H., Zarei, D., "Effect of nanoclay on corrosion protection of zinc-rich epoxy coatings on Steel 37”, Journal of Materials Science \& Technology, 32: 1152-1160, (2016).

[8] Mostafaei, A., Nasirpouri, F., "Epoxy/polyaniline-ZnO nanorods hybrid nanocomposite coatings, "Synthesis, characterization and corrosion protection performance of conducting paints", Progress in Organic Coatings, 77(1): 146-159, (2014).

[9] Olad, A., Barati, M., Behboudi, S., "Preparation of PANI/epoxy/Zn nanocomposite using Zn nanoparticles and epoxy resin as additives and investigation of its corrosion protection behavior on iron", Progress in Organic Coatings, 74(1): 221-227, (2012).

[10] Demirci, M.T., Tarakçıglu, N., Avcı, A., Akdemir, A., Demirci, I., "Fracture toughness (Mode I) characterization of $\mathrm{SiO}_{2}$ nanoparticle filled basalt/epoxy filament wound composite ring with splitdisk test method", Composites Part B: Engineering, 119: 114-24, (2017).

[11] Ramezanzadeh, B., Attar, M.M., Farzam, M., "Effect of $\mathrm{ZnO}$ nanoparticles on the thermal and mechanical properties of epoxy-based nanocomposite", Journal of Thermal Analysis and Calorimetry, 103: 731-739, (2011). 
[12] Barletta, M., Vesco, S., Puopolo, M., Tagliaferri, V., "Graphene reinforced UV-curable epoxy resins: Design, manufacture and material performance", Progress in Organic Coatings, 90: 414-424, (2016).

[13] Haeri, S. Z., Ramezanzadeh, B., Asghari, M., "A novel fabrication of a high performance $\mathrm{SiO}_{2}$ grapheneoxide (GO) nanohybrids: Characterization of thermal properties of epoxy nanocomposites filled with $\mathrm{SiO}_{2}-\mathrm{GO}$ nanohybrids", Journal of Colloid and Interface Science, 493: 111-122, (2017).

[14] Ramezanzadeh, B., Attar, M. M., "Studying the corrosion resistance and hydrolytic degradation of an epoxy coating containing ZnO nanoparticles", Materials Chemistry and Physics, 130(3): 1208$1219,(2011)$. 